\title{
A Irmandade do Santíssimo Sacramento de Campinas na confluência do religioso e do secular (1847-1908)
}

\author{
The Brotherhood of the Blessed Sacrament of Campinas \\ at the confluence of the religious and the secular
}

(1847-1908)

ANA Rosa ClocLet da SiLVA ${ }^{a}$

GABRIEL DE BARROS AMSTALDEN ${ }^{b}$

\section{Resumo}

O artigo analisa aspectos da reforma e atuação da Irmandade do Santíssimo Sacramento na cidade de Campinas, no período de 1847 a 1908. Pautada em documentação de natureza diversificada, objetiva compreender o papel desempenhado por esta instituição leiga, na confluência da Igreja institucional, da política e da religiosidade local. Para tanto, valoriza a atuação pessoal de alguns de seus membros na construção e manutenção das condições simbólicas e materiais da devoção ao Santíssimo Sacramento, bem como aspectos circunstanciais do contexto recortado: a cidade de Campinas. Como argumento central, sustenta que o perfil desta associação pode ser melhor compreendido antes pela sua tendência colaborativa, que de resistência às diretrizes da Igreja institucional, no contexto das reformas ultramontanas. O que significa reconhecer a complexidade dos processos históricos, no decorrer dos quais o religioso e o secular modelaram-se de maneira recíproca.

Palavras-chave: Irmandade do Santíssimo Sacramento. Reformas ultramontanas. Religiosidade. Campinas.

\footnotetext{
a Pontifícia Universidade Católica de Campinas (PUC-Campinas), Campinas, SP, Brasil. Doutora em História, e-mail: anacloclet@gmail.com

b Pontifícia Universidade Católica de Campinas (PUC-Campinas), Campinas, SP, Brasil. Mestre em Ciências da Religião, e-mail: gaamstalden@hotmail.com
} 


\section{Abstract}

The article analyzes aspects of the reform and performance of the Brotherhood of the Blessed Sacrament in the city of Campinas, from 1847 to 1908. Guided by diverse documentation, it aims to understand the role played by this institution, in the confluence of the institutional Church, politics, and local religiosity. Therefore, it values the personal performance of some of its members in the construction and maintenance of the symbolic and material conditions of devotion to the Blessed Sacrament, as well as circumstantial aspects of the context: the city of Campinas. As a central argument, it argues that the profile of this association can be better understood by its collaborative tendency rather than resistance to the guidelines of the institutional church in the context of ultramontane reforms. This means recognizing the complexity of the historical processes in the course of which the religious and the secular shaped up reciprocally.

Keywords: Brotherhood of the Blessed Sacrament. Ultramontane reforms. Religiosity. Campinas.

\section{Introdução}

A produção acadêmica no Brasil referente a Irmandades leigas é bastante significativa, sobretudo a que se refere ao período áureo da mineração em Minas Gerais. Conforme reconhecido pela historiografia, desde as primeiras descobertas auríferas, realizadas no final do século XVII, a mineração introduziu uma ocupação mais densa do que se verificou em outras regiões da colônia, e favoreceu o desenvolvimento de uma sociedade e de uma economia mais diversificadas (FONSECA, 2003, p. 40).

Tal fato se explica, em parte, pelos limites de atuação impostos à Igreja, que no Brasil permaneceu, desde a época colonial até a Constituição de 1891, vinculada institucionalmente ao Estado, no âmbito do regime de Padroado. De tal forma que, se por um lado a longa vigência do padroado delineou um campo religioso marcado pela supremacia do catolicismo - até certo ponto reconhecido como a única religião verdadeira, por outro, colaborou para enfraquecer o caráter institucional da Igreja não existindo, durante todo o período colonial, um “sujeito igreja capaz de estabelecer objetivos próprios, e estratégias para alcançá-los, com independência da coroa” (DI STEFANO, 2012, p. 209). 
Esta configuração, além de dificultar a ação evangelizadora da instituição, tornava a Igreja dependente da ação das Ordens religiosas, assim como das organizações leigas, representadas pelas irmandades e confrarias. Conforme o clássico estudo de Caio Boschi, limitada pelo Estado metropolitano, "não restou à Igreja outro recurso senão o de atrelar-se às associações leigas, mais para a prática de seus ofícios do que para uma política evangelizadora" (BOSCHI, 1986, p. 23).

Embora tenha sido um caso à parte, Minas não foi o único quadrante da sociedade colonial a contar com a relevância religiosa, política e social alcançada por essas associações leigas ${ }^{1}$, realidade esta que também se preserva durante o século XIX, nos marcos da construção do Estado nacional brasileiro. Tal fenômeno vem sendo percebido e acompanhado pela pesquisa acadêmica $^{2}$, que progressivamente passou a abranger outras províncias e a romper com a excessiva ênfase no período colonial, conforme perspectiva que orienta o presente estudo, cujo objetivo é analisar aspectos concernentes ao papel da Irmandade do Santíssimo Sacramento na cidade de Campinas, no período que vai de 1847, data da sua reorganização, até 1908, quando acontece a criação do bispado campineiro.

A abordagem eleita se situa na confluência da religião institucional, do político e da religiosidade local, no contexto que coincide com a implementação das reformas ultramontanas no Brasil. Como nos mostra Santirocchi (2015), no contexto destas reformas, durante a segunda metade do século XIX, algumas Irmandades leigas representaram uma certa resistência frente aos rumos tomados pelo Estado e pela Igreja católica, tendo como um de seus desdobramentos mais paradigmáticos a "Questão Religiosa" (1872-

\footnotetext{
${ }^{1}$ No caso da capitania de Minas Gerais, tal situação foi agravada uma vez que a exploração mineradora fez com que a vigilância do Estado recaísse com maior ênfase sobre a região, desde inícios do século XVIII. Por isso, foi aí proibida a presença de ordens religiosas, que em outras partes da América portuguesa representaram agentes fundamentais da evangelização, com destaque para o papel tradicionalmente representado pela Companhia de Jesus.

${ }^{2}$ Nesta perspectiva, alguns trabalhos recentes demonstra como o Estado brasileiro, sob os moldes do regalismo, resistiu à normatização romana sobre irmandades, as quais, por sua vez, "não caminhavam no sentido de contestar a legitimidade da autoridade eclesiástica, mas sim garantir os privilégios que, num processo de longa duração, foram sendo sedimentados nas mãos das irmandades em virtude da relação particular da Igreja e do Estado e da marcante presença leiga no catolicismo brasileiro" (OLIVEIRA, 2001, p. 155). Ver ainda as contribuições de: SANTOS, 2009; ABREU, 1999; VALENTE, 2011).
} 
1875)33. Porém, como sugere o próprio autor, esta marca da resistência não pode ser generalizada, o que nos instiga a problematizar tal perfil das Irmandades leigas e justifica o recorte eleito pela presente pesquisa, que avalia criticamente tal tendência, à luz do caso eleito.

Assim, como argumento central o presente artigo sustenta que, potencialmente, as Irmandades serviram como braços das próprias reformas ultramontanas, conforme os interesses e a compreensão de seus integrantes acerca do papel da instituição na realidade política e na religiosa local ${ }^{4}$. Daí a proficuidade de enfoques que tem explorado as relações entre recortes micro e as variáveis macro históricas, que ressaltam a especificidade de cada momento histórico, dos agentes envolvidos e das conjunturas nas quais estiveram inseridos. Nessa perspectiva, um comportamento não é mais consequência mecânica da obediência a uma norma, havendo escolhas e opções, conforme as contingências consideradas (REVEL, 1998, p. 155).

No caso eleito pelo presente artigo, significa relacionar o contexto das reformas orientadas pela Santa Sé, sob moldes tridentinos, ao panorama religioso, político e social no qual a Irmandade do Santíssimo Sacramento estava inserida: a cidade de Campinas. Para tanto, serão consideradas fontes primárias de naturezas diversas, incluindo documentos oficiais, emitidos pela própria Irmandade estudada - como livros de Ata e Assembleias - e pela hierarquia eclesiástica, como aqueles do bispado de São Paulo, normatizando aspectos da religiosidade popular, à luz das diretrizes vindas da Santa Sé —,

\footnotetext{
${ }^{3}$ A "Questão Religiosa", como ficou conhecida, foi uma série de acontecimentos envolvendo a Igreja Católica, a maçonaria e o Governo Imperial, os quais repercutiram profundamente nas relações entre o Trono e o Altar. Iniciaram em virtude da condenação imposta ao padre José Luís de Almeida Martins pelo bispo do Rio de Janeiro, D. Pedro Maria de Lacerda, em represália ao fato daquele ter discursado na comemoração da Lei do Ventre Livre, organizada pela loja Maçônica Grande Oriente do Lavradio, em homenagem ao Visconde do Rio Branco - José Maria da Silva Paranhos - grão-mestre maçom e Presidente do Conselho de Ministros do Império. Esta decisão foi apoiada pelos bispos do Pará - D. Antônio Macedo Costa - e o da diocese de Pernambuco - D. Vital - que em cumprimento às decisões pontifícias que condenavam a maçonaria, "requereram que as irmandades retirassem do seu grêmio os membros que pertenciam a dita sociedade secreta". O episódio levou as confrarias que se recusaram a cumprir tal determinação a apresentarem um "recurso à Coroa", que foi acatado, resultando ainda na condenação e prisão dos referidos bispos (SANTIROCCHI, 2015, p. 427).

${ }^{4}$ Refiro-me, por exemplo, à contribuição de Luciano Dutra Neto em sua pesquisa intitulada "Das terras baixas da Holanda às montanhas de minas" (2006), referente à ação dos redentoristas no Brasil, durante o período das reformas ultramontanas.
} 
mas também não oficiais e que extrapolavam a circulação no âmbito institucional, como era o caso da imprensa periódica da época. Através deste último veículo, Irmandades leigas divulgavam suas atividades junto à sociedade campineira, o que nos permite acessar sua inserção por um viés colaborativo com as reformas ultramontanas, convocando a população a participar de celebrações e da promoção de festas e procissões religiosas, emprestando vigor à vida religiosa local. Por fim, atentando para a confluência do religioso e do secular, será considerada a atuação de membros da Irmandade do Santíssimo Sacramento na vida política local, registrada nas Atas da Câmara Municipal, instância de representação política local, da qual fizeram parte alguns dos mais renomados integrantes da associação leiga aqui analisada.

Desse modo, com vistas a aprofundar os estudos acerca do papel das Irmandades leigas na implementação das reformas ultramontanas no Brasil da segunda metade do século XIX - se como focos de resistências a estas, ou possíveis braços de Roma - , a partir dos vínculos estabelecidos entre Igreja institucional, política e religiosidade local, o presente artigo se estrutura em duas partes principais. Num primeiro momento, situa o contexto da reforma da Irmandade do Santíssimo Sacramento de Campinas, tendo em vista seus impulsos locais mas, também, os condicionantes mais gerais que, naquele momento, atrelavam potencialmente tal reforma às diretrizes da Santa Sé, em seu esforço de romanização das Igrejas nacionais. A partir desta contextualização, que permite vislumbrar a atuação de alguns atores influentes na instituição leiga estudada e na vida política e religiosa local, pretende-se analisar o significado da Irmandade do Santíssimo Sacramento como mediadora entre o institucional e a religiosidade popular campineira.

\section{A Reforma da Irmandade do Santíssimo Sacramento e seus condicionantes}

Historicamente, a Irmandade do Santíssimo Sacramento remonta ao ano de 1538 quando, sob o papado de Paulo III e a administração do padre Tomaz Stela, ela surgiu na igreja dos dominicanos em Roma, com o intuito de prestar sua devoção a Deus, representado na Santa Eucaristia e tendo como 
obrigação a máxima frequência possível dos fiéis às missas, procissões e a constante adoração ao "Prisioneiro do Tabernáculo" (RODRIGUES, 1947, p. 9). Surgia, assim, uma associação voltada à devoção e ao cuidado com aquilo que é o ponto central da devoção católica, principalmente após o Concílio de Trento (1545-1563): o sacramento da Eucaristia5.

Este dogma, portanto, justificava a presença destas irmandades nas comunidades locais, demandando um templo digno a tal devoção e a própria manutenção do mesmo, o que explica congregarem, tradicionalmente, as camadas mais abastadas da sociedade (PAVONNE, 2015, p. 23). No Brasil este perfil foi acentuado, na medida em que a longa vigência do regime do padroado tornou a Igreja institucional desprovida de recursos e autonomia para suprir as necessidades de natureza religiosa, justificando a importância da participação dos leigos de cada novo arraial, vila ou cidade, na viabilização da presença do corpo de Cristo naquela determinada localidade.

A partir daí, a vida religiosa poderia acontecer, sobretudo no tocante ao sacramento da Eucaristia, que por razões pontuais, naquela época, assumia um caráter ainda mais divino e sagrado do que atualmente, já que não era corriqueiro, ocorrendo geralmente apenas uma vez por ano, durante a Semana Santa, ocasião em que se verificava "um verdadeiro fascínio pelo sacramento do altar que suscitava grande número de missas prescritas em testamentos" (OLIVEIRA, 2015, p. 10).

Outro dado histórico interessante é a vinculação do Santíssimo Sacramento à Igreja Matriz de cada localidade, fazendo com que a mesma importância e reverência devidas ao sacramento da Eucaristia fossem refletidas nos templos, onde:

\footnotetext{
O Santíssimo deveria ocupar o altar-mor das Igrejas Matrizes e, por conseguinte, os sacrários - espaço que armazenava a Eucaristia - os quais eram revestidos de toda suntuosidade, além dos objetos necessários ao Culto - o cálice e a custódia, que eram, geralmente, feitos de ouro ou prata e, algumas vezes, cravejados com pedras preciosas" (PAVONNE, 2015, p. 23).
}

\footnotetext{
${ }^{5}$ Foi durante o Concílio de Trento que a Igreja estabeleceu algumas recomendações sobre como e quando a comunhão deveria e poderia ser realizada e sob quais condições o fiel deveria se enquadrar para receber o sacramento. É nesse momento, por exemplo, que a confissão dos pecados e a sua absolvição passam a ser requisitos fundamentais, como forma de purificação, para que a pessoa pudesse tomar parte no Corpo de Cristo (PAVONE, 2015, p. 20).
} 
Sendo a presença da eucaristia tão importante para o bom funcionamento e atendimento da religião, era imprescindível a ereção de um templo e a posse de recursos para a manutenção do mesmo, o que explica a necessidade de atrair as pessoas de maior pompa social. “Dessa maneira, as Igrejas Matrizes deveriam ser eretas pelos irmãos do Santíssimo e a renda utilizada nas obras era, em grande parte, proveniente da receita da Irmandade, composta pela contribuição dos associados da Confraria" (OLIVEIRA, 2015, p. 24).

Outro fator de primordial importância era a organização de procissões e festas religiosas com o intuito de elevar ao máximo o prestígio e a devoção a Deus. As comemorações envolvendo diretamente o Santíssimo Sacramento eram as que demandavam uma atividade mais próxima e cuidadosa dos irmãos do Santíssimo, como eram os casos da Semana Santa e da procissão de Corpus Christi (PAVONNE, 2015, p. 22)

Dadas estas tradicionais funções, embora não se possa precisar a data de criação da Irmandade do Santíssimo Sacramento de Campinas, é certo que ela existia já no momento anterior ao marco inicial desta pesquisa, a partir de sua ligação direta com a Matriz da Conceição, onde "houve, desde os seus primórdios, o SS. Sacramento", bem como "uma irmandade para honrar o Divino Prisioneiro" (RODRIGUES, 1947, p. 22). Desde 1847, essa Irmandade foi reorganizada, reconfigurando suas funções em interação com a Igreja institucional, com o poder político local e com a própria religiosidade popular.

Neste sentido, vale lembrar que o período recortado (1847-1908) coincide com a fase crucial de implementação das reformas ultramontanas no Brasil. Na Diocese de São Paulo - à qual a Irmandade do Santíssimo de Campinas pertenceu até 1908 - , estas reformas foram iniciadas pelo bispado de D. Joaquim Antônio de Melo (1851-1861), através de um conjunto de medidas que envolveram, sobretudo, a reforma dos seminários — visando a formação do clero - , as visitas pastorais e a prática devocional da população (WERNET, 1987).

Alguns aspectos dessas reformas agiram diretamente sobre as irmandades leigas, muitas das quais possuíam em seu corpo membros da maçonaria, organização combatida pela ortodoxia católica e condenada em 
dois documentos emitidos pelo papa Pio IX, em 1864: a Encíclica Quanta Cura - que deveria oferecer uma síntese dos erros relacionados à sociedade moderna e, especialmente, à questão da liberdade de consciência —, seguida pelo Syllabus - uma lista contendo tais erros, representando a resposta ortodoxa da Igreja católica à sociedade contemporânea.

Nos últimos anos, novas possibilidades de abordagem historiográfica sobre as reformas ultramontanas e sobre como estas afetaram as irmandades leigas vem sendo realizadas por estudiosos do tema. Conforme se constata, um dos mais tensos momentos nestas relações foi representado pelos episódios que levaram à "Questão Religiosa" (1872-1875), os quais envolveram diretamente os bispos ultramontanos Dom Antônio Macedo Costa (do Pará) e Dom Vital (de Olinda), o Estado imperial, algumas irmandades leigas e a maçonaria, cujos membros frequentavam estas associações leigas (SANTIROCCHI, 2015, p. 427).

Na diocese de São Paulo, tais acontecimentos parecem ter reverberado tardiamente. É o que demonstra uma portaria assinada pelo então bispo de São Paulo, D. Joaquim Arcoverde, que apenas em 1895 excluía das irmandades as pessoas que pertencessem "a qualquer sociedade secreta de qualquer denominação que seja e as que nela depois entrarem", declarando "ilegítimas e ilegais quaisquer corporações que de futuro se seguirem ou reformarem nesta Diocese sem o pleno e fiel cumprimento dessas nossas determinações" (ACMSP, livro 2.3.10, p. 91v.). Além desta medida, determinava a obrigatoriedade das irmandades de "prestar contas da administração de seus bens à Autoridade Diocesana ou ao seu delegado", além de fazerem observar "eleições gerais ou parciais" à presidência da mesa um "Pároco ou por um eclesiástico em qualidade de representante do Bispo Diocesano, sob pena de nulidade" (ACMSP, livro 2.3.10, p. 91v.).

\footnotetext{
${ }^{6}$ Sinal tardio, por se tratar de uma recomendação posterior ao processo da Proclamação da República em 1889, e da própria Constituição de 1891, que punha fim ao padroado. A nosso ver, esse novo contexto permitiu não só ao bispo de São Paulo, mas aos prelados no Brasil de um modo geral, agirem de forma mais enérgica com relação às reformas a serem implementadas no corpo das irmandades, uma vez que sobre suas decisões já não pesavam mais o regalismo institucional.
} 
Todas estas recomendações a serem incorporadas aos estatutos das irmandades visavam subordiná-las ao controle e influência direta da Igreja, além do fortalecimento da figura do bispo. Para o caso analisado, porém, tal influência não se aplica a priori, pois são posteriores à reforma da Irmandade do Santíssimo. A nosso ver, mais importante que as orientações da Igreja romana, a reforma desta Irmandade parece ter respondido às circunstâncias locais, residindo na elevação da Vila de São Carlos a Cidade de Campinas um dos seus principais motivos. Isso porque, em 1846, foi agendada uma visita do então Imperador Dom Pedro II e sua comitiva a Campinas, fato que, segundo o memorialista João Lourenço Rodrigues — responsável por um primeiro levantamento histórico da irmandade feito em comemoração ao centenário da sua reorganização em 1947 - impusera a necessidade de uma ampla mobilização dos “homens da governança local” (RODRIGUES, 1947, p. 14), a fim de conferir a tal acontecimento a pompa que lhe cabia.

Com a existente relação entre Igreja e Estado nos moldes do padroado, era de se esperar uma recepção a Dom Pedro II na Igreja Matriz da cidade, como comumente ocorria nas demais localidades por ele visitadas. Porém, em Campinas a Igreja Matriz remontava à época de Barreto Leme, histórico fundador da cidade, e se encontrava em estado precário, não estando à altura do ilustre visitante. Embora a construção da nova Matriz já tivesse sido iniciada no ano de 1809, a obra estava longe de ser concluída. A solução encontrada foi instalar provisoriamente a Matriz da Conceição na Igreja do Rosário, que possuía uma estrutura mais apropriada para tal acontecimento. As providências foram tomadas e no dia 26 de março de 1846, a comitiva imperial chegou à cidade e tudo ocorreu com a pompa programada: "Os festejos duraram três ou quatro dias. Depois que partiu o imperial visitante, a vida citadina voltou ao ritmo habitual, mas durante muitos dias ficaram os campineiros sob a impressão dessas horas inolvidáveis" (RODRIGUES, 1947, p. 15).

A mudança da Matriz da Conceição para a Igreja do Rosário implicava, também, a ida da Irmandade do Santíssimo, já existente nesse período e que deveria sempre estar representada na Igreja Matriz. Neste ponto, outro motivo pode ser aventado como causa de sua reorganização, em 1847: o fato de já existir na Igreja do Rosário uma irmandade religiosa - a de Nossa 
Senhora do Rosário - já muito bem organizada e estruturada, de tal forma que "ela se sentiu em plano inferior pelo que diz respeito à piedade" (RODRIGUES, 1947, p. 15)

A piedade era um dos pontos principais para a agremiação de uma Irmandade e, sendo assim, era pertinente que seus membros se perguntassem como poderia uma irmandade historicamente vinculada às camadas mais ricas da sociedade e ao próprio Santíssimo Sacramento, ser inferior a outra que, historicamente, agremiava negros e escravos (SALLES, 2007, p. 87). Assim, a visita imperial e a mudança da Igreja Matriz para a Igreja do Rosário nos parecem ser os motivos mais plausíveis para o início da reforma da Irmandade do Santíssimo, decisão esta registrada em Ata do dia 6 de junho de 1847.

Além da referida Ata da assembleia, que elegeu a mesa administrativa para o ano de $1847^{7}$, outro documento registra o início da nova fase do sodalício campineiro. Trata-se de uma portaria do então bispo de São Paulo, Dom Manuel Joaquim Gonçalves de Andrade, datada de 17 de fevereiro do mesmo ano, pela qual reconhecia e aprovava o novo Compromisso da Irmandade ${ }^{8}$. Com essa aprovação, os membros puderam então realizar a eleição já nos moldes do novo estatuto.

Para além desses fatos relacionados à busca de reconhecimento e necessidade de sobressair-se em relação a outras irmandades locais, uma outra razão que parece ter colaborado para a iniciativa de reforma da Irmandade é a necessidade de uma prática religiosa mais efetiva, tanto no seio da própria Irmandade, quanto na cidade de Campinas. Em nível da igreja institucional, tal preocupação afinava-se às prioridades do bispo ultramontano de São Paulo, D. Antônio Joaquim de Melo, que em Carta Pastoral datada de 6 de junho de 1852, apresentava-se à sua Diocese relatando todos os problemas segundo ele enfrentados pela Igreja na segunda metade do século XIX. Dentre estes, incluía a falta de interesse do povo com a "vida eterna, ocupados só com o que é do mundo", cuja causa era atribuída tanto à falta de educação do clero - de forma que "o sal, que devia preservar o povo da podridão moral, tornou-se insulso, tonou-se inútil” —, quanto à “falta absoluta de educação católica aos

\footnotetext{
${ }^{7}$ Livro Ata de Assembleia $n^{\circ} 1$. Arquivo da Irmandade do Santíssimo Sacramento de Campinas

${ }^{8}$ Livro no 7-3-43. p.129. Arquivo ACMSP.
} 
meninos e aos moços, e, enfim, o abandono da confissão anual" (ACMSP, livro 2-2-17, p. 104).

Sintonizado com estas preocupações, um personagem em específico teve direta participação na reorganização do sodalício campineiro: o senhor Antônio Francisco Guimarães. Português de nascimento e erradicado no Brasil, primeiramente na Bahia — de onde trouxe consigo o apelido de "Baía”, pelo qual tornou-se conhecido - , deixou um grande legado não só à Irmandade, mas à própria cidade de Campinas, ajudando a revigorar a prática católica. Auxiliou diretamente na construção da Matriz Nova e futura Catedral de Campinas $^{9}$, a qual representa, ainda hoje, um marco histórico e arquitetônico. Com sua vivência e experiência no âmbito religioso, o "Baía” encontrou na cidade uma instituição fragilizada e uma religiosidade muito aquém daquela que ele considerava o ideal para uma sociedade em franco desenvolvimento, como era o caso de Campinas. A tendência de âmbito nacional era atribuída à constante ausência de padres para rezar as missas, por conta de seus envolvimentos com seus negócios privados, mais do que com o próprio povo e sua missão espiritual. Em Campinas, tal situação não parecia ser diferente, conforme descrito pelo memorialista João Lourenço Rodrigues, ao citar um relato de Benedicto Octávio, segundo o qual:

Sem dúvida existia aqui fé e pregava-se a doutrina, mas a religião mantinha-se apenas com o caráter tradicional. Basta dizer que as igrejas só se abriam de manhã e por ocasião das grandes festividades. Devoção nenhuma a não ser, aos domingos, as saudosas bênçãos que, na Igreja da Misericórdia, dava o seu digno capelão, Padre Francisco G. Thevenon" (RODRIGUES, 1947, p. 22).

Um dado interessante do cenário brasileiro nesse período e que se aplica ao caso campineiro, é trazido por Luiz Roberto Benedetti, o qual observa uma mudança da representatividade das cidades e da Igreja para os grandes

\footnotetext{
${ }^{9}$ A tradição popular de Campinas "criou" os termos Matriz Velha e Matriz Nova para diferenciar as duas igrejas que foram originalmente construídas para abrigar a santa padroeira da cidade, Nossa Senhora da Conceição. Posteriormente a historiografia campineira vai também se apropriar desses termos para fazer referência às igrejas. A chamada Matriz Velha é a primeira igreja Matriz da cidade construída em 1870, já a Matriz Nova foi inaugurada em 1883 para ser a nova sede da padroeira, em dimensões e imponência bem maiores. Ambas estão localizadas no centro da cidade e hoje, no local onde se encontrava a "Matriz Velha" está a Basílica de Nossa Senhora do Carmo.
} 
fazendeiros e detentores de poder na época, que continuavam a auxiliar na ereção e manutenção dos templos, sendo que muitos deles o faziam através da vinculação a irmandades religiosas. Este envolvimento dos abastados locais tem seu ápice com criação da diocese de Campinas, em 1908, mas já pode ser observado com reorganização da Irmandade do Santíssimo, que prenuncia as novas alianças da Igreja com os comerciantes, além de consolidar aquela já existente com os barões do café (BENEDETTI, 1983, p. 109-110).

Tal contexto parece pertinente para explicar o papel representado por Antônio Francisco Guimarães na reorganização da Irmandade do Santíssimo, o qual encontrou na cidade outras figuras dispostas a auxiliar nas mudanças necessárias. Para tanto, um de seus aliados foi Joaquim José Vieira, nomeado vigário encomendado de Campinas, em 1860, e que mais tarde se tornaria um dos bispos de tendência ultramontana do Ceará. Segundo João Lourenço Rodrigues, empenhado em "trazer moldes novos à vida espiritual dos campineiros" e exercendo uma atuação mais próxima aos fiéis, o padre Vieira — apelidado de "Vigarinho" - , apesar da pouca idade, logo caiu nas graças da população e se tornou muito querido (RODRIGUES, 1947, p. 24). Porém, o período de sua atuação em Campinas ainda estava inserido no quadro do regalismo institucional, com a forte influência do Estado nas decisões envolvendo a Igreja. Assim, por influência do partido Liberal, que à época se encontrava no poder, não conseguiu ser nomeado Vigário colado, cargo este assumido, no dia 24 de abril de 1864, pelo padre Joaquim de Sousa Oliveira.

Apesar de ter sido preterido para o cargo de Vigário Colado (PAULA, 1972, p. 50), o padre Vieira seguiu com a sua atuação pastoral, sendo inclusive o capelão da Irmandade do Santíssimo Sacramento e agindo para a continuação e aprimoramento da religião em Campinas. Tendo ele a preocupação com as obras de caridade e o cuidado com as almas, manteve boa relação com uma ala progressista existente entre moradores proeminentes de Campinas, do que resultou a construção da Santa Casa de Misericórdia de Campinas (RODRIGUES, 1947, p. 40).

Decorrido então esse momento inicial da reorganização da Irmandade do Santíssimo Sacramento, ela passa a ter uma vida ativa e influente na realidade da cidade. O estatuto passa a ser seguido com mais rigor e, consequentemente, as contribuições dos irmãos previstas no "Compromisso" 
também são cumpridas com maior seriedade. O florescer financeiro, que acontece em um primeiro momento a partir dessas contribuições, possibilita o investimento posterior em imóveis e no comércio campineiro. A Irmandade passa a fazer uso de alguns dispositivos que eram utilizados também por suas antecessoras mineiras, como o aluguel de utensílios e paramentos para uso nas celebrações (RODRIGUES, 1947, p. 33).

O caráter religioso da Irmandade também se afirma rapidamente após a sua reorganização. A frequência de missas ofertadas pela própria Irmandade ou pelos irmãos aumenta, assim como a participação dos mesmos nas cerimônias. A assistência prestada aos irmãos é outro dispositivo presente desde os primórdios das irmandades e que passa a ter maior efetividade desde 1847: missas em prol da alma dos irmãos falecidos, os cuidados fúnebres, tudo passa a ter um olhar mais dedicado do sodalício (AISSC, Livro I). O avanço financeiro também propicia aquisições significativas para a irmandade, que adquire inúmeros conjuntos de prata - como vasos e castiçais, alfaias ricamente trabalhadas, imagens devocionais -, a fim de elevar o culto do Santíssimo Sacramento à importância que lhe cabia ${ }^{10}$.

A importância conquistada pela Irmandade do Santíssimo Sacramento se revela, também, uma das premissas principais para seus membros terem erigido um cemitério próprio dos irmãos do Santíssimo. Por fim, sintoma da vitalidade da irmandade leiga aqui estudada e que revela sua forte influência na vida religiosa local, a partir de 1847, se refere ao sino principal da torre da igreja que hoje é a Catedral Metropolitana de Campinas. O objeto foi doado pelo ilustre membro da Irmandade, Antônio Francisco Guimarães, que cedeu inclusive o seu apelido de "Baía" ao sino, na época em que era ainda a Matriz Velha a principal igreja da cidade. O que torna esse acontecimento relevante é um dispositivo existente no termo de doação do sino, através do qual o mesmo só pode ser utilizado em eventos e celebrações que envolvam diretamente a Irmandade do Santíssimo Sacramento, tendo como punição, em caso de descumprimento, a retirada do objeto da torre da igreja (RODRIGUES, 1947, p. 12).

\footnotetext{
${ }^{10} \mathrm{Grande}$ parte desse acervo artístico compõe hoje o museu da Irmandade, que se encontra sob os cuidados do Museu Arquidiocesano de Arte Sacra de Campinas.
} 
Tal sino foi colocado primeiramente na Matriz Velha e, posteriormente, com o término da construção, transferido para a Matriz Nova (O ESTADO de S. PAULO, 1929, ed. 18.324, p. 11). Porém, o dispositivo acordado na doação se manteve, reiterando aspectos do tradicional poderio que, desde o período colonial, algumas irmandades observaram.

\section{2 - A Irmandade reformada na confluência do religioso e do secular}

Uma vez reformada, a Irmandade do Santíssimo Sacramento funcionou como verdadeiro mediador entre o institucional e a religiosidade popular campineira. Num contexto em que a cidade de Campinas foi duplamente envolvida pelas reformas ultramontanas e pelos ideais de progresso e civilização, legitimadores do novo regime republicano, a atuação de membros da Irmandade sintonizados com estes ícones estendeu-se à imprensa local, como comprova o periódico Gazeta de Campinas, que circulou de 1869 até 1889. e cujo acervo se encontra digitalizado pela Biblioteca Nacional ${ }^{11}$. Através deste veículo, fomentaram a vida religiosa na cidade, seguindo o exemplo de outras irmandades aí existentes ${ }^{12}$.

A maioria das ocorrências sobre as irmandades campineiras no periódico consultado fazem referência à convocação de seus membros para eleição ou posse da mesa administrativa, o que demonstra o funcionamento regular das irmandades, que a esse tempo, já se encontravam sob o olhar mais próximo dos bispos reformadores. São recorrentes, também, as publicações convidando a população para participar das celebrações, procissões e festas religiosas promovidas por essas irmandades. Neste aspecto, porém, a atuação da Irmandade do Santíssimo Sacramento não se faz tão presente no fluxo de publicações, tendo destaque as irmandades de São Benedito e de Nossa

\footnotetext{
${ }^{11}$ O acervo da Gazeta de Campinas se encontra digitalizado e disponível no site da Hemeroteca Digi Hemeroteca Digital da Biblioteca Nacional. Disponível em: <http://memoria.bn.br/hdb/periodico.aspx>.

${ }^{12}$ As publicações comprovam a existência de pelo menos seis irmandades, divididas entre a paróquia de Nossa Senhora da Conceição (a Matriz da cidade) - com as Irmandades do Santíssimo Sacramento; de Nossa Senhora - e a paróquia de Santa Cruz - com a irmandade do Rosário e de São Benedito. Todas fundadas a partir de 1860, perdurando até os dias atuais.
} 
Senhora das Dores. O que atribuímos à sua importância já consagrada, que dispensava a divulgação de suas atividades através da imprensa, permitindo que sua atuação fosse direcionada para mecanismos mais tradicionais, como o empenho na construção da Matriz Nova e uma maior estruturação da Igreja institucional, como demonstra o caso do "Sino do Baía", cujos dispositivos de utilização foram impostos pelo seu próprio doador, Antônio Francisco Guimarães, em sessão da Irmandade datada de 6 de junho de 1847 (RODRIGUES, 1847, p. 11). Embora fosse de se esperar, não houve qualquer posicionamento refratário da Igreja institucional quanto às condições de uso do sino, sugerindo a boa relação existente entre os membros da Irmandade leiga e a Igreja institucional.

Outros documentos demonstram a participação direta da Irmandade do Santíssimo na construção da Matriz Nova, atual Catedral Metropolitana de Campinas. Um desses exemplos é o requerimento do procurador da Irmandade, o sr. Manuel Gonçalves Vieira, no qual solicita no dia 3 de julho de 1848 a liberação da Câmara Municipal de Campinas, para a "construção de espaço" na lateral da Matriz Nova, para as necessidades da Irmandade (ACMC, Livro 142, p. 62). A Irmandade possuía, ainda, uma harmoniosa relação com o pároco da Matriz, o ultramontano Joaquim José Vieira, não parecendo serem estes agentes dos conflitos entre Igreja e Estado, reprisados em outras partes do Brasil e, sobretudo, no contexto da Questão Religiosa (RODRIGUES, 1947, p. 27).

À mesma época, outras irmandades apropriaram-se fortemente da imprensa, talvez por não disporem tão fartamente de dispositivos tradicionais de influência local. Assim, em edição datada do dia 30 de março de 1871, era relatada a benção de uma nova imagem de Nossa Senhora das Dores, encomendada pela Irmandade de mesmo nome e que aconteceu na paróquia de Santa Cruz, com a presença do padre Joaquim José Vieira e grande participação popular. Segundo o jornal:

A benção foi feita com as formalidades do ritual; e, finda ela, subiu ao púlpito o reverendo padre Vieira que, em um breve e brilhante improviso, mostrou a necessidade e utilidade que há na Religião Católica de celebrar-se o culto externo, e o dever que tem todo católico de prestar homenagem e veneração à Mãe do Redentor (Gazeta de Campinas, 1871, ed. 143, p. 2). 
Já a Irmandade de São Benedito publica, em 28 de dezembro de 1871, um anúncio e um convite aos seus membros e demais cidadãos, para participarem das celebrações em comemoração ao referido Santo, o qual era "feito a expensas de particulares" e não acontecia há oito anos, "como era de costume em tempos atrasados" (Gazeta de Campinas, 1871, ed. 219, p. 3 ).

Os casos mencionados corroboram a sintonia da atuação das referidas irmandades com as recomendações de reforma dos costumes da sociedade e participação dos fiéis na vida religiosa das paróquias, ditadas pelas reformas ultramontanas. Por sua vez, ao considerar aspectos da vida religiosa local, a Igreja concorda e participa dos eventos realizados pelas irmandades, mesmo durante o período efervescente de conflitos entre os bispos reformadores e as associações leigas em outras partes do país, contrariando as recomendações vindas de Roma, com relação à postura do clero sobre a religiosidade popular.

Esse efervescer religioso, a partir da atuação de irmandades religiosas durante a segunda metade do século XIX, contraria algumas vertentes da historiografia, que defendem a suposta decadência dessas agremiações, se comparadas ao século anterior. É fato que existe uma diferenciação entre a atuação dessas irmandades, se as compararmos com o período colonial. Porém, é possível conjecturar com a hipótese de que tenha sido mais uma mudança e uma adaptação na sua forma de atuação, do que propriamente uma decadência, pois, não parece haver grandes conflitos entre a Igreja institucional e aspectos da religiosidade popular na cidade, no contexto observado e, tampouco, com as Irmandades leigas.

Constatação que confirma uma das hipóteses inicialmente aventadas por este trabalho: de que as Irmandades, não necessariamente, foram focos de resistência às diretrizes ultramontanas que orientavam a Igreja institucional, podendo mesmo serem vistas como congruentes com as diretrizes da Santa Sé, no sentido de fomentar e modelar hábitos e comportamentos dos fiéis, valorizando os sacramentos, a frequência ao culto, etc.

Anderson José Machado de Oliveira, analisa um exemplo dessa adaptação, através do seu estudo sobre as irmandades na Corte do Rio de Janeiro (OLIVEIRA, 1995). Com o avanço da postura modernizadora e as necessidades que surgiam em torno de uma aproximação com as chamadas 
"nações civilizadas" europeias, o Estado brasileiro passa a intervir na melhoria dos espaços urbanos, legislando sobre a limpeza das vias públicas e obras de infraestrutura. Com isso, as irmandades passaram a adaptar os seus compromissos, a fim de manter entre seus membros apenas aqueles que estivessem em consonância com os padrões e posturas sociais e religiosas aceitos pela Igreja e pelo Estado. Assim, por exemplo, a Irmandade da Santa Cruz dos Militares, em compromisso de 1857, exigia daqueles que desejassem filiação a apresentação de atestado de sanidade, que por vontade da mesa, poderia ser alvo de posterior verificação (OLIVEIRA, 1995).

Em Campinas podemos notar sinais desse posicionamento referentes à atuação individual de alguns membros da Irmandade do Santíssimo, visando a melhoria urbana e estrutural da cidade. Um levantamento realizado a partir do conjunto dos documentos da Irmandade do Santíssimo Sacramento e da Câmara Municipal de Campinas revela que, entre 1832 e 1896, ao menos oito membros da Irmandade foram também presidentes da Câmara Municipal, fato que demonstra a proeminência política desses irmãos na sociedade campineira.

Além dos requerimentos já citados sobre a colocação do sino em frente à Matriz e à construção de espaço destinado à Irmandade na Matriz Nova, a presença dos irmãos do Santíssimo na Câmara municipal visava uma série de melhorias públicas para a cidade, com olhos para o grande desenvolvimento desta. Entre 1850 e 1854, são vários os requerimentos referentes ao cuidado de ruas, estradas e calçadas de diversas regiões da cidade. Esse desenvolvimento da infraestrutura urbana também era de interesse pessoal de alguns dos membros, já que proviam melhorias para suas propriedades e favoreciam ainda os seus negócios a partir da estruturação e construção de novas estradas para o transporte de mercadorias, por exemplo.

Mas é possível notar, também, o constante cuidado com a manutenção do culto, haja vista as diversas participações em sessões da Câmara com o intuito de conseguirem recursos para melhorias das igrejas. Assim: Antônio Francisco Guimarães, o "Baía”, solicitava, em 25 de abril de 1851, obras de reparo tanto na Igreja do Rosário, quanto na de Santa Cruz (ACMC, Livro 143, pg. 41v); em 12 de abril de 1853, o sr. Antônio Joaquim de Sampaio Peixoto, membro da Irmandade, diretor municipal do censo e futuro delegado, foi 
nomeado o administrador das obras de construção da Matriz Nova (ACMC, Livro 143, pg. 90v); em 25 de janeiro de 1854, outro membro da Irmandade, o sr. José Francisco de Paula abria requerimento junto à Câmara, a fim de comprar a Matriz Velha, para que servisse de Igreja Matriz até a conclusão das obras da Matriz Nova (ACMC, Livro 143, p. 123,v. 41).

Tendo em vista o contexto mais geral das reformas ultramontanas e o fato já destacado pela historiografia, acerca das "medidas tomadas pelo governo e pelos bispos ultramontanos que objetivavam afastar o clero dos movimentos sediciosos e da política partidária" (SANTIROCCHI, 2011), chama a atenção a participação do próprio padre Vieira na vida política da cidade. Porém, a Gazeta de Campinas nos apresenta alguns artigos que comprovam a participação do "Vigarinho" no processo eleitoral municipal, tendo inclusive concorrido para o cargo de vereador.

Assim, em publicação do dia 22 de agosto de 1872, um artigo apresenta a composição das "mesas paroquiais" de votação e nele está citado o padre Joaquim José Vieira, bem como o senhor Antônio Joaquim de Sampaio Peixoto, também membro da Irmandade do Santíssimo (Gazeta de Campinas, 1872, ed. 282, p. 3). Já no dia 5 de setembro de 1872, temos o relato do padre Vieira enquanto candidato ao cargo de vereador, ao lado de nomes importantes como do Barão de Três Rios (Joaquim Egídio de Souza Aranha, membro da Irmandade), Bento Quirino dos Santos e do dr. Campos Salles, demonstrando a importante presença política do prelado (Gazeta de Campinas, 1872, ed. 286, p. 2).

Apesar de não ter sido eleito, o fato de o padre Joaquim José Vieira ter participado do processo eleitoral e ter concorrido ao cargo de vereador, mais uma vez nos mostra indícios do diálogo existente entre um representante institucional da Igreja católica com a vida política local, contrariando algumas das determinações do Estado imperial e dos bispos reformadores, com destaque para Dom Antônio Joaquim de Melo (1851-61), precursor das reformas ultramontanas no bispado de São Paulo.

Membros da Irmandade do Santíssimo Sacramento também estiveram presentes nas Comissões e Diretórios responsáveis pelas obras de construção da Matriz Nova. É o caso do sr. Joaquim Egídio de Souza Aranha, o Barão de 
Três Rios, nomeado para tal função no ano de 1870 (Gazeta de Campinas, 1870, ed. 82, p. 2).

No entanto, o fato de membros da Irmandade terem presença marcada na esfera do poder político local nem sempre garantia sucesso nas suas reivindicações. Em sessão da Câmara Municipal, do dia 10 de fevereiro de 1872, entrou o sr. Antônio Francisco Guimarães com um requerimento, a fim de revogar a determinação da própria Câmara de venda de um espaço em frente ao cemitério da Irmandade. O mesmo requerimento foi indeferido, sob alegação de que "essa concessão feita outrora ficou sempre a arbítrio da Câmara revogá-la; além da poderosa razão de estar hoje o largo cortado pela linha férrea" (Gazeta de Campinas, 1872, ed. 237, p. 1).

Podemos notar que, mesmo a Irmandade tendo relevância política e social na cidade, os interesses econômicos e ideais de progresso e modernização prevaleciam, uma vez que a decisão da Câmara levou em consideração a existência da linha férrea, responsável pelo transporte de mercadorias e de escoamento da produção cafeeira daquela cidade, que já então era reconhecida como a "Princesa d'Oeste" paulista.

\section{Conclusão}

A análise da reforma e atuação da Irmandade do Santíssimo Sacramento de Campinas, na conjuntura recortada, é reveladora do quanto as relações destas associações leigas, seja com a Igreja institucional, seja com a religiosidade popular, ou com a própria política local, esteve longe de obedecer a um padrão previsível e passível de generalização. Além disso, se por um lado não se pode ignorar a influência das diretrizes da Santa Sé sobre as Igrejas nacionais e as associações leigas, por outro, o caso analisado é revelador da importância assumida pela atuação de alguns de seus membros, cujos interesses, objetivos, escolhas, pesaram decisivamente para além da suposta rigidez imposta pela dimensão macro-histórica. Assim, por exemplo, percepções e entendimentos muito particulares orientaram sua participação direta na área política e econômica local, bem como o grande investimento, tanto financeiro quanto humano, na construção da Nova Igreja Matriz da cidade. 
A atuação individual de seus membros em sessões da Câmara municipal, reivindicando melhorias de ordem pública e estrutural, bem como representando a própria Irmandade em assuntos relacionados à construção da Matriz Nova ou à realização de obras envolvendo o cemitério do sodalício, demonstra o posicionamento adotado pela instituição durante a segunda metade do século XIX, em sintonia tanto com o progresso urbano, quanto com a tradição religiosa. Atuação esta que, aliada à ausência de relatos de conflitos entre a Irmandade do Santíssimo e a Igreja institucional, no período analisado, sugere que a sintonia da agremiação leiga com as reformas ultramontanas, ainda quando filtrando algumas das diretrizes dos bispos reformadores e do próprio Estado imperial.

A partir destas reflexões, esperamos contribuir com os estudos que têm pensado a construção recíproca do religioso e do secular, do institucional e do popular, do sagrado e do profano, configurando experiências concretas de “modernidade religiosa” (DI STEFANO, 2012). Enquanto algumas destas articulações se revelaram comuns ao mundo católico da época, outras foram profundamente marcadas por particularidades nacionais, regionais e mesmo locais - como atesta o caso campineiro - , as quais devem ser valorizadas e cujos vínculos devem ser explorados.

\section{Referências}

ABREU, M. O Império do Divino: festas religiosas e cultura popular no Rio de Janeiro, 1830 - 1900. Rio de Janeiro: Nova Fronteira; São Paulo: FAPESP, 1999. 406p.

ARQUIVO da Cúria Metropolitana de São Paulo (ACMSP): Livro 2.3.10, p. 91v; Livro n 73-43, p.129; livro 2-2-17, p. 104.

ARQUIVO da Câmara Municipal de Campinas (ACMC): Livro 142, pg. 62; Livro 143, pg. 90v ; Livro 143, pg. 123,v. 41.

ARQUIVO da Irmandade do Santíssimo Sacramento de Campinas (AISSC): Livro Ata de Assembleia $\mathrm{n}^{\circ} 1$.

BENEDETTI, L. R. Os Santos Nômades e o Deus Estabelecido. São Paulo: Edições Paulinas, 1993.

BOSCHI, C. C. Os leigos e o poder (Irmandades Leigas e política colonizadora em Minas Gerais). São Paulo: Editora Ática, 1986. 
DI STEFANO, R. ¿De qué hablamos cuando decimos "Iglesia”? Reflexiones sobre el uso historiográfico de un término polisémico. Ariadna histórica. Languajes, conceptos, metáforas, Buenos Aires, n. 1, 2012.

DUTRA NETO, L. Das terras baixas da Holanda às montanhas de Minas. Uma contribuição à história das missões redentoristas, durante os primeiros trinta anos de 164 trabalho em Minas Gerais. 2006, Tese de doutorado, Universidade Federal de Juiz de Fora - Programa de Pós-Graduação em Ciência da Religião, 315p.

FONSECA, C. D. Funções, hierarquias e privilégios urbanos - A concessão dos títulos de vila e cidade na Capitania de Minas Gerais. Varia História, Belo Horizonte, n. 29, jan., 2003.

GAZETA DE CAMPINAS, 1860 - 1889. ed. 237, 1872; ed. 82, 1870; ed. 286, 1872; ed. 282, 1872; ed. 219, 1871; ed. 143, 1871. Disponível em: Acervo BND <http://bndigital.bn.gov.br/hemeroteca-digital/>. Acesso em: 11 out. 2019.

OLIVEIRA, A. J. M. Os bispos e os leigos: reforma católica e irmandades no Rio de Janeiro Imperial. Revista de História Regional, v. 6, n. 1, p. 147-160, 2001.

OLIVEIRA, A. J. M. A administração do sacramento da ordem aos negros na América Portuguesa: entre práticas, normas e políticas episcopais (1702-1745), Locus - Revista de História, v. 21 n. 2, 2015, p. 416-442.

OLIVEIRA, A. J. M. Devoção e Caridade: irmandades religiosas no Rio de Janeiro Imperial (1840-1889). Dissertação (Mestrado em História) — Universidade Federal Fluminense, UFF, Niterói, 1995.

O ESTADO de S. PAULO, 1929, ed. 18.324, p. 11. Disponível em: <https://acervo.estadao.com.br/>. Acesso em: 10 dez. 2019.

PAULA, C. F. Santa Casa de Misericórdia de Campinas - Primeiro Centenário. São Paulo: Empresa Gráfica da Revista dos Tribunais, 1972.

PAVONNE, M. O. Associações religiosas leigas nas Minas Gerais nos séculos XVIII e XIX. Belo Horizonte: Cilo Editora, 2015.

REVEL, J. Jogos de escalas a experiência da microanálise. Rio de Janeiro: Editora Fundação Getúlio Vargas, 1998.

RODRIGUES, J. L. A vida religiosa de Campinas através do histórico da Irmandade do SS. Campinas: Sacramento da Catedral, 1947.

SALLES, F. T. Associações Religiosas no Ciclo do Ouro. 2. ed. São Paulo: Perspectiva, 2007.

SANTIROCCHI, I. D. Questão de Consciência: os Ultramontanos no Brasil e o Regalismo do Segundo Reinado (1840-1889). Belo Horizonte: Fino Traço, 2015. 
SANTOS, B. Irmandades, oficiais mecânicos e cidadania no Rio de Janeiro. Tese (Doutorado) - UFF, Rio de Janeiro, 2009.

SILVA, A. L. Devoções Populares no Brasil: Contextualizando Algumas Obras das Ciências Sociais. São Paulo: Rever, 2003.

VALENTE, A. "As irmandades de negros: resistência e repressão”. HORIZONTE, Belo Horizonte, p. 202-219, mar. 2011.

WERNET, A. A igreja paulista no século XIX. São Paulo: Ática, 1987.

RECEBIDO: 14/12/2019

Aprovado: 27/04/2020
RECEIVED: $12 / 14 / 2019$

APPROVED: 04/27/2020 